\title{
Effect of Operating Conditions on the Removal of Heavy and Radioactive Elements by Reverse Osmosis Membrane
}

\author{
Waleed T. Rashid ${ }^{a *}$, Israa A. Alkadir $^{a}$, and Moayyed G. Jalhoom ${ }^{b}$ \\ ${ }^{a}$ Production and Metallurgy Engineering Department, University of Technology/Baghdad \\ ${ }^{b}$ Consultant- Production and Metallurgy Engineering Department, University of Technology/Baghdad
}

\begin{tabular}{l} 
A R T I C L E I N F O \\
\hline Article history: \\
Received 5 July 2020 \\
Received in revised form 16 Augu \\
Accepted 15 September 2020 \\
Keywords: \\
Heavy and Radioactive Elements \\
Reverse Osmosis \\
Rejection \\
Flux Permuted
\end{tabular}

\begin{abstract}
A B S T R A C T
The major goal of the presented study is to study the Reverse Osmosis (RO) characteristics for $(\mathrm{Cd}, \mathrm{U}, \mathrm{Pb}$, $\mathrm{Cu}, \mathrm{Zn}, \mathrm{K}$, Th, and Ni) removal from an aqueous solution containing Phosphogypsum. This was performed done by examining the impact related to temperature and pressure on the performance regarding the RO membrane in the removal of elements with time. Values of temperatures $(25,35$, and $450 \mathrm{C})$ and various pressures such as (2, 4 and 6 bars) were used in this work. It was found that, as the pressure increases, the flux permitted and rejection of elements would be increased, where were the values of maximum rejection of elements 81,90.9,90.9,77.5,80.2,93.9,92.9 and 76.6\% for $\mathrm{Cd}, \mathrm{U}, \mathrm{Pb}, \mathrm{Cu}, \mathrm{Zn}, \mathrm{K}$, Th, and $\mathrm{Ni}$ respectively, when operating time 90 minutes and pressure 6 bar. The temperature increases the flux permitted while the rejection of elements was steady state almost with the increase in temperature for all heavy and radioactive elements. It was also shown shows that these a steady-state has stopped after $35^{\circ} \mathrm{C}$ and rejection start to decrease until reaching 75,85.4,86.2,73.8,74,91.2,86.2 and $69 \%$ for $\mathrm{Cd}, \mathrm{U}, \mathrm{Pb}, \mathrm{Cu}, \mathrm{Zn}, \mathrm{K}, \mathrm{Th}$, and $\mathrm{Ni}$ respectively.
\end{abstract}

\section{Introduction}

Phosphogypsum (PG) can be defined as a solid waste by-product that is created throughout phosphoric acid's production from the phosphate rocks with the use of the process "wet acid" Al-Hwaiti et al. [1]. This waste has been presently responsible for more than $90 \%$ of the production of phosphoric acid. Globally, generating PG has been approximately 280 million tons per year (2010) Perez-Lopez et al. [2]. Yet, just 15\% regarding the production of PG in the world has been recycled as building materials Zhou et al. [3], Agricultural fertilizers, soil amendments, and asset manufacturing Portland cement Degirmenci et al. [4]. The other $85 \%$ regarding the production of PG in the world have been disposed of with no treatment. Such by-product has been dumped typically in the large stockpiles, and after that subjected to weathering processes, occupy significant lands and resulting in damage to the environment (chemical and radioactive contamination) Shweikani et al. [5]. Phosphogypsum mainly consists of calcium sulfate dihydrate $\left(\mathrm{CaSO}_{4} \cdot 2 \mathrm{H}_{2} \mathrm{O}\right)$ and contains a high level of impurities originating from the source phosphate rock that is utilized in the production of phosphoric acid. From such impurities, radionuclides from $238-\mathrm{U}$ and $232-\mathrm{Th}$ decay series have been a major concern because of their radiotoxicity. Furthermore, there are other elements; including heavy metals and Rare Earth Elements (REEs) have

* Corresponding author.

E-mail address: waleed_eng99@yahoo.com (Waleed T.Rashid) 
been enriched in PG. The United States Environmental Protection Agency (USEPA) defined PG as "Technologically Enhanced Naturally Occurring Radioactive Material” (TENORM), since it generally consists of trace amounts regarding thorium, uranium, in addition to daughter products from actinides decay chains (radon and radium) Calin et al. [6]. Approaches to remove metal ions from the aqueous solutions majorly involve physical methods as well as chemical ones. Traditional methods to remove metal ions from the aqueous solutions were fumigation, flotation methods, ion exchange, filtration, chemical precipitation, electrochemical treatment, adsorption on effective charcoal, etc. Santos et al. [7]. In this study, reverse osmosis has been used to remove heavy and radioactive elements from the leach solution, because this method has advantages in removing contaminated elements. Efficient use of the (RO) membrane has been documented for the transaction of $\mathrm{Cr}$ and cyanide metal-plated wastewater Abdullah et al. [8]. In the membranes, the separation of the particle fulfillment in a sieve-like approach, in which the membrane's small pores allow the passage regarding extremely small molecules whereas retaining large particles. RO can be considered as a separation process which applies pressure for forcing solutions through a membrane, retaining the solute on one side as well as allowing the passing of pure solvent to the other. In such case, the membrane is considered to be semipermeable, which means that it will allow the passage regarding solvent, yet not for the metals. The RO membranes utilized are the dense barrier layer in a polymer matrix in which the majority of separation takes place. RO has the ability to remove different types of ions and molecules from the solutions; RO includes diffusion method so that the separation efficiency will be based on water flux rate, pressure, as well as solute concentration Papageorgiou et al. [9]. Many ways used the recuperation of trace elements with various acids from phosphogypsum, however, they are economically expensive and have a negative environmental impact. This study has chosen water as the solvent for the phosphogypsum treatment and recovers the heavy and radioactive elements. In addition, reverse osmosis is often used to treat hospital waste and wastewater. In this study, used the reverse osmosis method as a complement to the leaching process to remove heavy and radioactive elements.

\section{Material}

A representative sample of the Phosphogypsum (which was used in this study) was obtained from the Al-Qaim fertilizers complex at the Al-Anbar government. Fig. 1, shows the main mineralogical phases of the Phosphogypsum sample which are (calcium sulphate) with other secondary minerals such as dolomite and brucite, where can be seen, the percentage of calcium sulphate has the largest proportion with a few percentages of dolomite and brucite impurities, while calcium sulphate was (93.6\%), dolomite (2.4\%), brocite (4.1\%). Table 1 shows the Chemical analysis of the sample which was performed by X-Ray Fluorescence (XRF). The atomic absorption spectroscopy type (nova AA 350) at Ibn-Sina state Co . labs. Used to determine the dissolved heavy and radioactive elements in the solution of the leaching process.

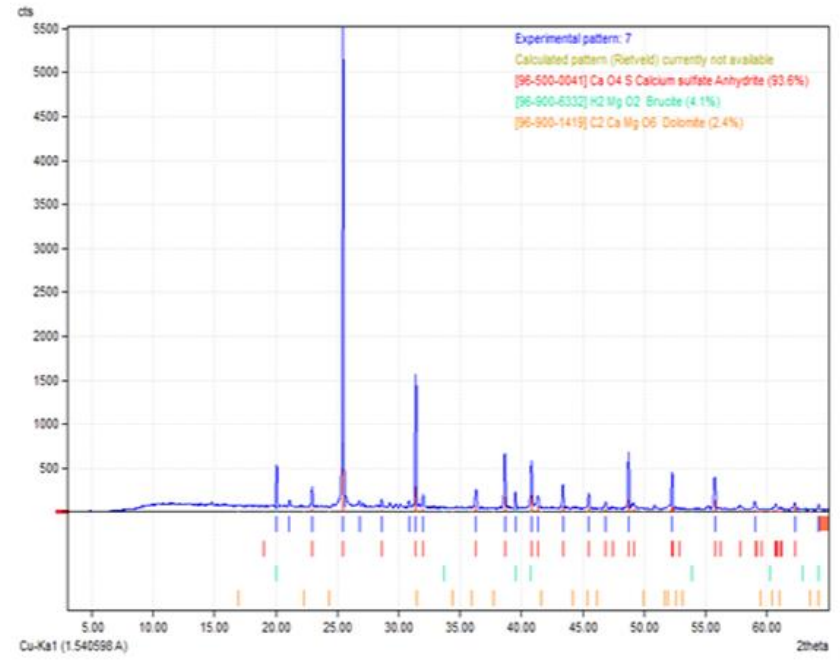

Figure 1. XRD pattern of Phosphogypsum

Table 1. XRF analysis of the sample

\begin{tabular}{|c|c|c|c|}
\hline Symbol & Concentration \% & symbol & Concentration \% \\
\hline MgO & 3.536 & $\mathrm{ZrO}_{2}$ & 0.00014 \\
\hline $\mathrm{Al}_{2} \mathrm{O}_{3}$ & 0.0038 & $\mathrm{Nb}_{2} \mathrm{O}_{5}$ & 0.00014 \\
\hline $\mathrm{SiO}_{2}$ & 1.152 & Mo & 0.00072 \\
\hline $\mathbf{P}_{2} \mathrm{O}_{3}$ & 2.006 & $\mathrm{Ag}$ & 0.00114 \\
\hline $\mathrm{SO}_{3}$ & 46.42 & $\mathrm{Cd}$ & 0.00020 \\
\hline $\mathbf{C l}$ & 0.05028 & $\mathrm{SnO}_{2}$ & 0.00107 \\
\hline $\mathbf{K}_{2} \mathbf{O}$ & 0.0675 & $\mathrm{Sb}_{2} \mathrm{O}_{5}$ & 0.00236 \\
\hline $\mathrm{CaO}$ & 36.91 & $\mathrm{Te}$ & 0.00101 \\
\hline $\mathrm{TiO}_{2}$ & 0.0082 & I & 0.00159 \\
\hline $\mathrm{V}_{2} \mathrm{O}_{5}$ & 0.0061 & Cs & 0.00040 \\
\hline $\mathrm{Cr}_{2} \mathrm{O}_{3}$ & 0.00073 & $\mathrm{Ba}$ & 0.02104 \\
\hline MnO & 0.00067 & $\mathrm{La}$ & 0.00020 \\
\hline $\mathrm{Fe}_{2} \mathrm{O}_{3}$ & 0.01769 & $\mathrm{Ce}$ & 0.00020 \\
\hline $\mathrm{CoO}$ & 0.00039 & Hf & 0.00010 \\
\hline $\mathrm{NiO}$ & 0.00185 & $\mathrm{Ta}_{2} \mathrm{O}_{5}$ & 0.01523 \\
\hline $\mathrm{CuO}$ & 0.00334 & WO3 & 0.00020 \\
\hline $\mathrm{ZnO}$ & 0.00890 & $\mathrm{Hg}$ & 0.00010 \\
\hline $\mathbf{G a}$ & 0.00005 & $\mathrm{TiO}_{2}$ & 0.00011 \\
\hline Ge & 0.00005 & $\mathrm{PbO}$ & 0.00114 \\
\hline $\mathrm{As}_{2} \mathrm{O}_{3}$ & 0.00007 & $\mathrm{Bi}$ & 0.00010 \\
\hline Se & 0.00005 & $\mathrm{Th}$ & 0.00010 \\
\hline $\mathrm{Br}$ & 0.00024 & $\mathrm{U}$ & 0.00150 \\
\hline $\mathbf{R} \mathbf{b}_{2} \mathbf{O}$ & 0.00006 & $\mathrm{Y}$ & 0.00285 \\
\hline SrO & 0.6326 & & \\
\hline
\end{tabular}




\section{Procedure of reverse osmosis}

Fig. 2, shows the reverse osmosis unit used. Phosphogypsum sample was used for each one of the tests, the feed should be prepared initially through dissolving the needed quantity of phosphogypsum $(0.64 \mathrm{~g} \backslash 1 \mathrm{~L})$ Jalhoom1 et al. [10], in deionized water with stirring speed 600 RPM contact time $30 \mathrm{~min}$., temperature $45^{\circ} \mathrm{C}$, and particles size $(-710+75 \mu \mathrm{m})$. The solution from the feed tank has was pumped with various pressures, in which pressure change via close regarding reject water's valve, which installed after pumps and before entering the membrane chamber (cell). The reading of feed stream pressure gauged for getting the required pressure for all operations. Following water preparation, depending on the needed specifications as well as pressure regulation, flow rate as well as other parameters as indicated, the system has been operating for not less than two minutes to reaching steady state. Meanwhile, permeate as well as the rejected water will be returning to the feed tank to maintain the concentration of water. Then, permeate and feed solution has been collected in a flask for testing amount regarding radioactive and heavy metals for calculating membrane rejection as well as determining permeate flow rate to estimate membrane flux. The operating condition using the reverse osmosis membranes process was commenced with the following $\div$ operation pressure, time, and temperatures. In this work, heavy and radioactive elements, that had been selected (Ni, $\mathrm{Zn}, \mathrm{Pb}, \mathrm{Cd}, \mathrm{Cu}, \mathrm{K}, \mathrm{U}$, and $\mathrm{Th}$ ).

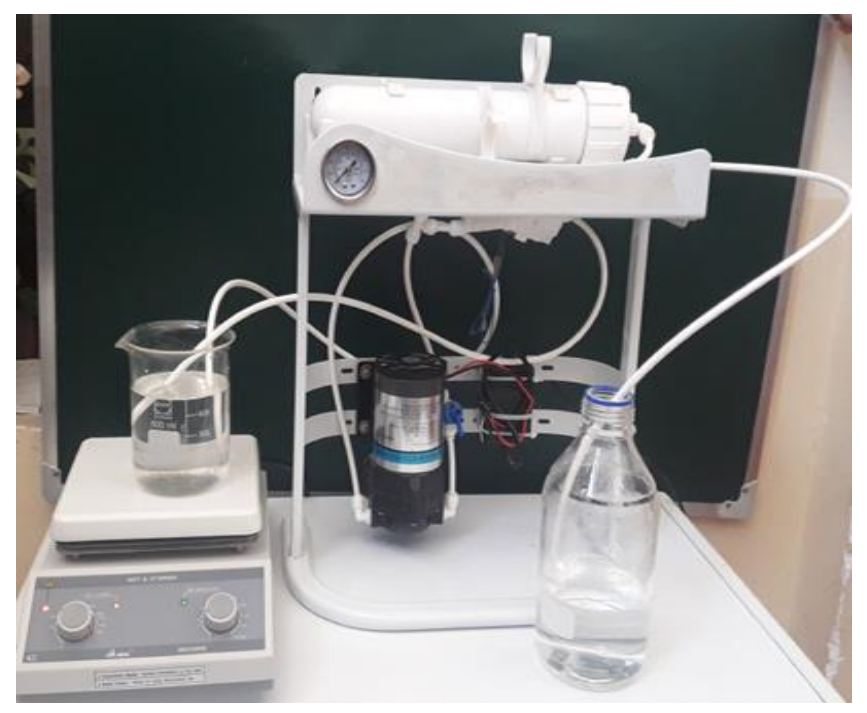

Figure 2. Reverse Osmosis Unit

\section{Performance of the reverse osmosis system}

\subsection{Rejection calculated}

The percentage of heavy and radioactive element rejection was calculated by using equation (1) Al-Masri et al. [11].

$$
\mathrm{R}(\%)=\frac{(\mathrm{C} 1-\mathrm{C} 2)}{\mathrm{C} 1} \times 100
$$

Where $(\boldsymbol{R})$ represents the rejection percentage, $\left(\boldsymbol{C}_{\mathbf{1}}\right),\left(\boldsymbol{C}_{2}\right)$ represent the concentration of the elements in the feed and in the permeate in the $(\mathrm{mg} / \mathrm{L})$, respectively. The elements concentrations in the permeate and the feed was determined using atomic absorption spectroscopy.

\subsection{Permeable flux calculated}

Permeate flux can be considered as the quantity regarding permeate created throughout membrane separation for each time as well as membrane area. Flux will be measured in liters for each square meter per hour. Solution permeability was measured to investigate the membrane performance. The permeable flux has been determined by equation (2) Gunatilake et al.[12].

$$
J=\frac{V}{A \times t \times p}
$$

Where $(J)\left(\mathrm{L} / \mathrm{m}^{2}\right.$.h.bar) is the permeable flux, $(V)$ (liter) is the volume of permeate, $(A)\left(\mathrm{m}^{2}\right)$ is the effective membrane surface area, $(t)$ (hour) is the time and $(\mathrm{P})(\mathrm{bar})$ is the pressure.

\section{Results and discussion}

\subsection{Effect of pressure and time on permeate flux}

Many factors are affecting the RO membrane performance. The main factors to be considered are temperature, time, and pressure. Fig. 3, shows the impact related to pressure on permeate flux under conditions, pressure (2-6) bar, time (220) minutes, and temperature $(25)^{\circ} \mathrm{C}$. It can be seen that increasing operating pressure from 2 to 6 bar led to an increase in permeate flux. This phenomenon can be explained by Darcy's law stating that increasing the pressure will consequently increase permeate flux Moslehyani et al. [13]. Higher pressure indicates that high driving force has been utilized across the membrane for pushing water molecules to pass through its semi-permeable membrane which might lead to higher permeates flux Arahman et al. [14]. Fig. 3 displays the impact of experiment time on permeate flux. The findings of this study show that the contact time has little effect on the permeate flux probably due to the concentration polarization in the system. Concentration polarization occurred because of the increment in the osmotic pressure that exists due to the tendency of water for moving from low solute concentrations to high solute concentrations. The effect of concentration polarization will result in reduced flux Nicolaisen et al. [15].

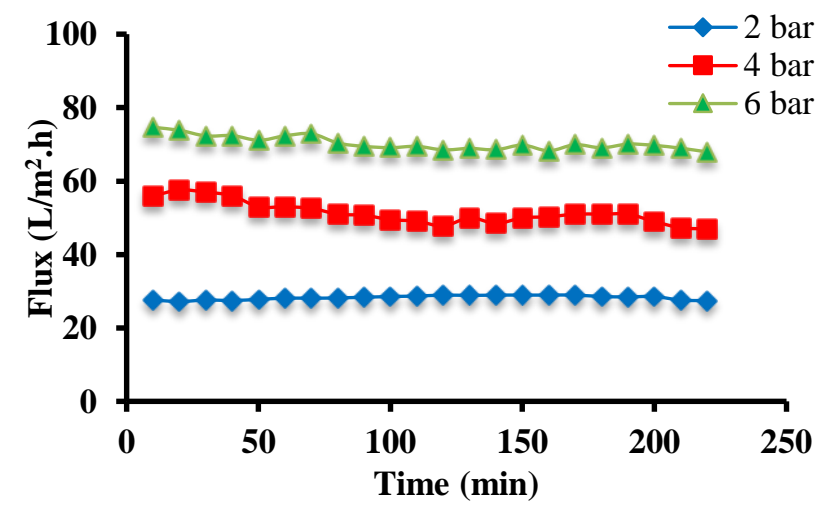

Figure 3. Effect of pressure on permeates flux by RO membrane 
Figs. 4,5 and 6 show the impact regarding pressure and experiment time on removing $\mathrm{Ni}, \mathrm{Zn}, \mathrm{Pb}, \mathrm{Cd}, \mathrm{Cu}, \mathrm{K}, \mathrm{U}$, and Th elements for the $\mathrm{RO}$ system. under conditions, the pressure (2-6) bars, time (60-120) minutes and temperature $(25)^{\circ} \mathrm{C}$. It might be indicated that removing metal ions will be increased with the increase in pressure from 2 bars to 6 bars. Similar results were obtained by R. W. Baker et al. [16]. This behavior because of is occurred due to the membrane does not prevent elements in the feed solution passing completely; therefore some elements pass through the membrane exists. In the case of increasing the pressure, the solution (solvent) will be pumped through the membrane at a high rate in comparison to metals ions Zhou et al. [17]. This relationship is in agreement with previous researchers that studied the effect of transmembrane pressure on ions rejection through the membrane separation process. Higher pressure lead led to a denser and compacted membrane structure Algureiri et al. [18]. As the membrane becomes more compact, molecules other than water will have difficulties passing through the membrane, hence increasing the rejection of molecules other than water in the treatment process Arkhangelsky et al. [19]. Figs. 4, 5, and 6 show the effect of time on the removal related to radioactive and heavy elements. It might be specified that the percentage rejection regarding radioactive and heavy elements increases slightly as time is increased; the removal efficiency has been improved because of fouling. Because of the fouling that arises with increased working time, there will be a decrease in the radius of the pores, which will cause difficulty in the passing of the metal ions, where similar results were obtained by Vignesh Nayak et al. [20], When increasing operating time, the removal of heavy elements was increased. The order of rejection is $\mathrm{K}>\mathrm{Th}>\mathrm{Pb}>\mathrm{U}>\mathrm{Cd}>\mathrm{Zn}>\mathrm{Cu}>\mathrm{Ni}$, presumably this result is due to reject the elements that have a large radius best than others that have a small radius.

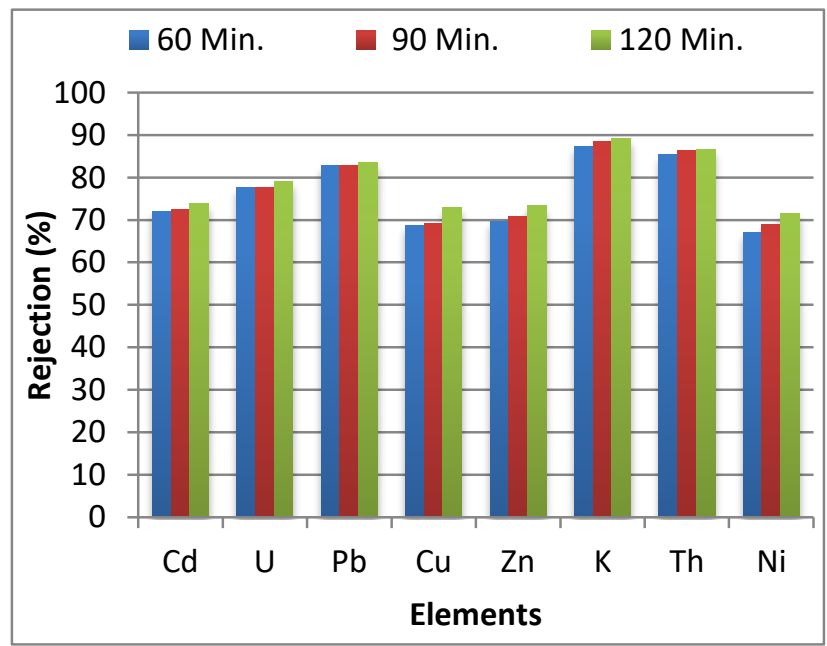

Figure 4. Effect of time on rejection ions by RO membrane at $2 \mathrm{bar}$

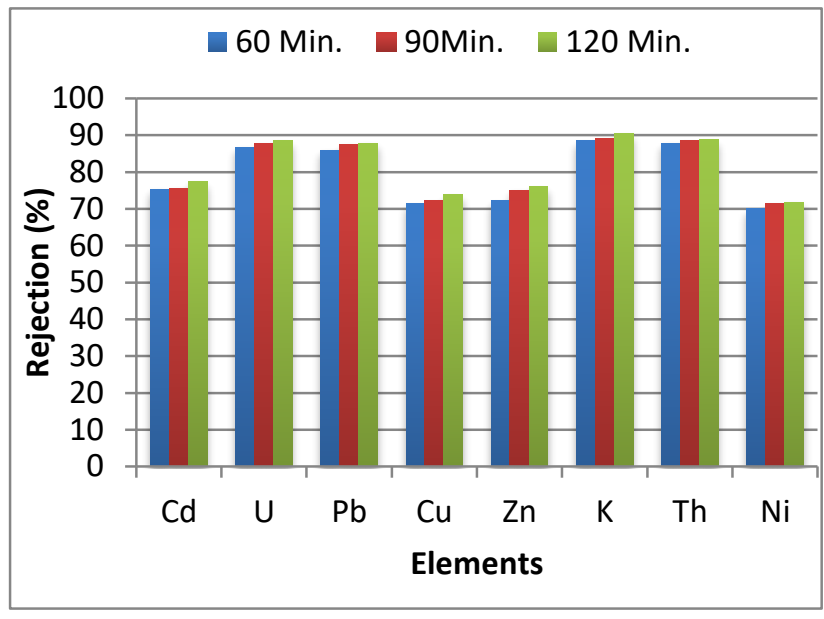

Figure 5. Effect of time on rejection ions by RO membrane at $4 \mathrm{bar}$

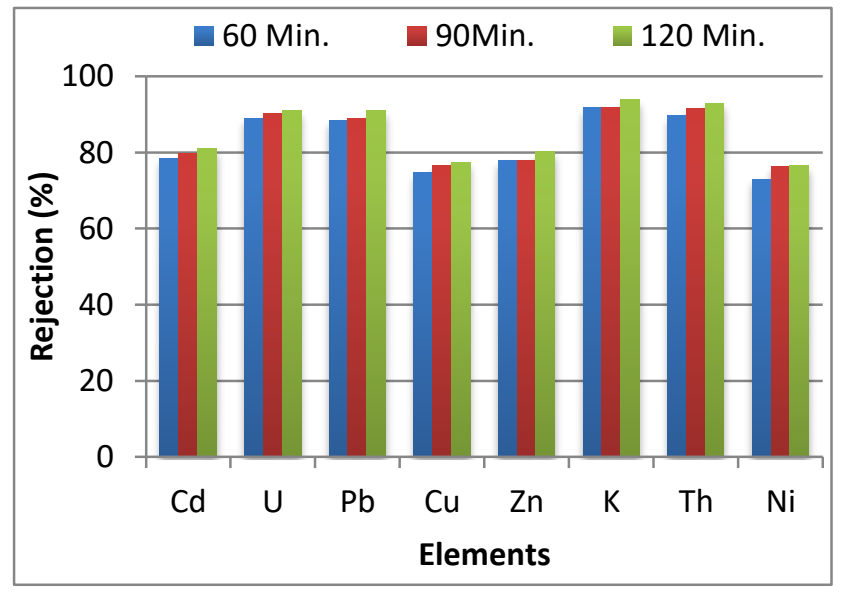

Figure 6. Effect of time on rejection ions by RO membrane at 6 bar

\subsection{Effect of temperature and time on permeate flux and rejection during the $\mathrm{RO}$ process.}

Fig. 7, shows the effect of the temperature on heavy and radioactive element rejection ( $\mathrm{Ni}, \mathrm{Fe}, \mathrm{Pb}, \mathrm{Ca}, \mathrm{Cu}, \mathrm{K}, \mathrm{U}$ and $\mathrm{Th}$ ), for reverse osmosis system under conditions the pressure (6) bar, time (60) minutes, and temperature (25-45 $)^{\circ} \mathrm{C}$. Fig. 7 demonstrates the effect of temperature on the rejection of heavy and radioactive elements. It can be seen that the rejection was steady-state to little decrease that slightly decreased proportionally with the increase in temperature for all heavy and radioactive elements. It also shows that these a the steady-state has stopped after $35^{\circ} \mathrm{C}$ and rejection starts to decrease. This process is occurred, because the membrane active work is in the temperature range of $\left(25-35^{\circ} \mathrm{C}\right)$. also it's material building at such conditions. The temperature's increase in within 
such range results in an imbalance in the membrane as well as pores' expansion that allows the pass of many ions across the membrane, which will be reducing the rejection process's efficiency. Lastly, with when the temperature is increased (more than $35^{\circ} \mathrm{C}$ ) as a result in of decreasing the element's elements removal since the elevated temperatures is occurred as a result in changes of the membrane material and holes expansion hence, will result in cause membrane damage which will allow entry of minerals and salts dramatically with the pure water Moideen et al. [21]. Such results have been in almost in accordance with S. Riaño et al. [22]. Fig. 8, displays the impact of temperature on permeate flux at pressure of (4) bars and time for (60) minutes and temperature $(25-45){ }^{\circ} \mathrm{C}$, for the RO membrane. The permeate flux increasing increases clearly with increasing temperature. Temperature increase led to an imbalance in the membrane structure therefore causing pores to expansions that allow the transit of a large amount of solution, also this is because of the decrease in the viscosity of water when increasing the temperature of feed water. The results are in good agreement results agreed with the previous work of S. Abdulmuttaleb Mohammed et al. [23], also from Fig. 8 it is can see be seen that the effect of the time on permeate flux, with as when increasing the operating time from 5-60 minutes, there is a slight decrease in permeate flux, this can be attributed to fouling.

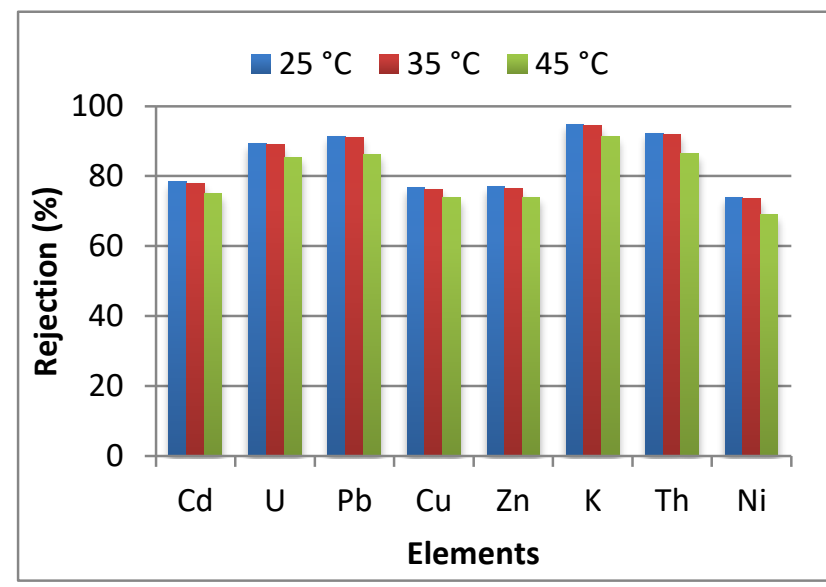

Figure 7. Effect of temperature on rejection of RO membrane.

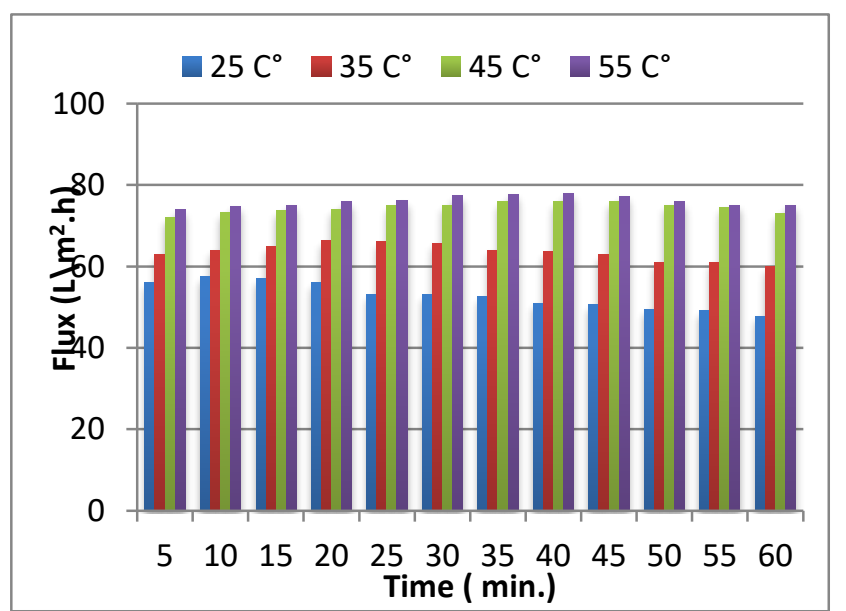

Figure 8. Effect of temperature and operating time on rejection of RO membrane.

\section{Conclusions}

This study leads to the following conclusions:

1. Both rejection and the permeation flux increase when increasing the pressure.

2. Increasing the rejection of heavy and radioactive elements with increasing time, while the permeation flux decreases when increasing the time.

3. The permeation flux is increasing with increasing temperature.

4. The rejection was steady-state almost with the increase in temperature until $\left(35^{\circ} \mathrm{C}\right)$ then decreases with the increase in temperature till $\left(45^{\circ} \mathrm{C}\right)$.

\section{REFERENCES}

[1] M. Al-Hwaiti, K. A. Ibrahim, and M. Harrara, "Removal of heavy metals from waste phosphogypsum materials using polyethylene glycol and polyvinyl alcohol polymers," Arab. J. Chem., 2015.

[2] R. Perez-Lopez, J. M. Nieto, I. Lopez-Coto, J. L. Aguado, J. P. Bolivar, and M. Santisteban, "Dynamics of contaminants in phosphogypsum of the fertilizer industry of Huelva (SW Spain): From phosphate rock ore to the environment," Appl. Geochemistry, vol. 25, no. 5, pp. 705-715, 2010.

[3] J. Zhou, Z. Sheng, T. Li, Z. Shu, Y. Chen, and Y. Wang, "Preparation of hardened tiles from waste phosphogypsum by a new intermittent pressing hydration," Ceram. Int., vol. 42, no. 6, pp. 7237-7245, 2016.

[4] N. Degirmenci, A. Okucu, and A. Turabi, "Application of phosphogypsum in soil stabilization," Build. Environ., vol. 42, no. 9, pp. 3393-3398, 2007.

[5] R. Shweikani, M. Kousa, and F. Mizban, "The use of phosphogypsum in Syrian cement industry: Radiation dose to public," Ann. Nucl. Energy, vol. 54, pp. 197-201, 2013.

[6] I. Calin, M. R., Radulescu and M. A. Calin, "Measurement and evaluation of natural radioactivity in phosphogypsum in industrial areas from Romania," J. Radioanal. Nucl. Chem., vol. 304, no. 3, pp. 1303-1312, 2015.

[7] A. J. G. Santos, B. P. Mazzilli, D. I. T. Favaro, and P. S. C. Silva, "Partitioning of radionuclides and trace elements in phosphogypsum and its source materials based on sequential extraction methods," J. Environ. Radioact., vol. 87, no. 1, pp. 52-61, 2006.

[8] N. Abdullah, N. Yusof, W.J. Lau, J. Jaafar, A.F.ismail," Recent Trends of Heavy Metal Removal from Water/wastewater by Membrane Technologies", Journal of Industrial and Engineering Chemistry,2019.

[9] F. Papageorgiou, A. Godelitsas, and T. J. Mertzimekis, "Environmental impact of phosphogypsum stockpile in remediated Schistos waste site ( Piraeus , Greece ) using a combination of $\gamma$-ray spectrometry with geographic information systems," Env. Monit Assess, vol. 188, 2016.

[10]. M. G. Jalhoom1, K. S. Al-Bassam and A. H. Humaidi ,"Recovery Of Some Trace Elements From Iraqi Phosphate Products", Iraqi Bulletin of Geology and Mining, No.7, , p 79 - 92,2017.

[11]. M. S Al-Masri., Amin Y.," The Use Of Biosorbents For Heavy Metals Removal From Aqueous Media", Syrian Arab Republic Atomic Energy Commission,2010.

[12] S.K Gunatilake," Methods of Removing Heavy Metals from Industrial Wastewater", Journal of Multidisciplinary Engineering Science Studies Vol. 1, pp.12-18,2015.

[13] A. Moslehyani, O. M. Nasser, R. Junin, E. Halakoo, A.F. Ismail ,'Polyethersulfone Ultrafiltration Membrane for Oil-in-Water Emulsion Separation", International Conference on Membrane Science \& Technology ,2013.

[14] N.Arahman," Modification of the Morphology of the Poly(ether sulfone) Membrane Prepared by Dry Phase Inversion Technique", 
International Journal of Applied Engineering Research, Vol.9, No. 21 ,pp. 10453-10462, 2014.

[15].B. Nicolaisen,'Developments in Membrane Technology for Water Treatment", Desalination, Vol.153, pp355-360, 2003.

[16] R. W. Baker,Membrane Technology and Application. 3rd Edition. John Wiley and Sons Ltd., 2012.

[17] W. Zhou, and L. Song, "Experimental Study of Water and Salt Fluxes Through Reverse Osmosis Membranes", Environment Science Technology. 39: pp3382-3387, 2005.

[18]. A. H. Algureiri and Y. R. Abdulmajeed," Removal of Heavy Metals from Industrial Wastewater by Using RO Membrane “,Iraqi Journal of Chemical and Petroleum Engineering, Vol.17 ,No.4,pp. 125- 136, 2016.

[19]. E. Arkhangelsky, V. Gitis. ,"Effect of Transmembrane Pressure on Rejection of Viruses by Ultrafiltration Membranes", Separation and Purification Technology,Vol. 62, increases, No.3,pp 619-628, 2008.

[20]. J. Vignesh Nayak , M. Padaki , R. Geetha Balakrishna , A.F. Ismail ," The effect of UV irradiation on PSf/TiO2 mixed matrix membrane for chromium rejection”, Desalination,Vol. 354, pp.189-199,2014.

[21]. I. Moideen K, A. M. Isloor, A.F. Ismail, Abdulrahman Obaid \& Hoong Kun Fun,"Fabrication and characterization of new PSF/PPSU UF blend membrane for heavy metal rejection", Desalination and Water Treatment,p.1-10,2015.

[22]. S. Riaño and K. Binnemans," Extraction and separation of neodymium and dysprosium from used $\mathrm{NdFeB}$ magnets: an application of ionic liquids in solvent extraction towards the recycling of magnets", The Royal Society of Chemistry,Green Chem., Nol.17, p.2931-2942, 2015.

[23]. S. Abdulmuttaleb Mohammed, Areej Dalaf Abbas, Laith Salim Sabri," Effect of Operating Conditions on Reverse Osmosis (RO) Membrane Performanceincreasing Journal of Engineering ,Number 12, Volume $20,2014$. 